\title{
Optimal Design of PID Controller for Doubly-Fed Induction Generator-Based Wave Energy Conversion System Using Multi- Objective Particle Swarm Optimization
}

\author{
Adel A.A. Elgammal \\ Utilities Engineering Department, The University of Trinidad \& Tobago UTT, Point Lisas Campus, Esperanza \\ Road, Brechin Castle, Couva, Trinidad and Tobago

\begin{abstract}
This paper presents the complete modeling and simulation of Wave Energy Conversion System (WECS) driven doubly-fed induction generator with a closed-loop vector control system. Two Pulse Width Modulated voltage source (PWM) converters for both rotor- and stator-side converters have been connected back to back between the rotor terminals and utility grid via common dc link. The closed-loop vector control system is normally controlled by a set of PID controllers which have an important influence on the system dynamic performance. This paper presents a Multi-objective optimal PID controller design of a doubly-fed induction generator (DFIG) wave energy system connected to the electrical grid using Particle Swarm Optimization (PSO) and Genetic Algorithm (GA). PSO and GA are used to optimize the controller parameters of both the rotor and grid-side converters to improve the transient operation of the DFIG wave energy system under a fault condition as compared with the conventional methods to design PID controllers.
\end{abstract}

Keywords: Grid integration, Wave Energy Conversion systems, Doubly-Fed Induction Generator (DFIG), Vector control, Genetic Algorithm GA, Particle Swarm Optimization PSO.

\section{INTRODUCTION}

Producing energy from renewable energy resources such as solar, wind, ocean, micro-hydro, biomass, etc is becoming a necessity because of the the continuous increasing of world energy demand. Since the abundance of wave power potential and its pollutionfree nature, wave energy can be considered as one of the attractive and green alternative energy sources in the world today [1-7]. The Doubly Fed Induction Generator (DFIG) is widely used in the development of distributed renewable energy sources [8], [9]. The rotor windings of the DFIG are arranged via the Rotor Side Converter (RSC) to allow an AC current to be injected by field orientation control to optimize the energy conversion and keep the terminal voltage constant for variable speed. The field orientation control based on proportional, integral and differential controllers (PID controllers) controls the active and reactive powers that the DFIG exchanges with the electrical grid. The aim of the field orientation control is to maximize the extracted power from the wave [10-15]. Suitable controller parameters highly improve system stability and performance. However, the online tuning of these parameters is difficult due to the nonlinearity and the high complexity of the system [16]. "Differential evolution (DE) is a population-based method and generally considered as a parallel stochastic direct

*Address correspondence to this author at the Utilities Engineering Department, The University of Trinidad \& Tobago UTT, Point Lisas Campus, Esperanza Road, Brechin Castle, Couva, Trinidad and Tobago; Tel: (868) 6428888 Ext. 32334; Fax: (868) 636-3339;

E-mail: adel_elgammal@ieee.org search optimizer which is very simple, precise, fast as well as robust algorithm" [17-19]. The DE can solve optimization problems with non-linear and multi-modal objective functions. Recently, intelligent optimization algorithms such as genetic algorithms (GAs), tabu search algorithm, simulated annealing (SA) and particle swarm optimization (PSO) have been successfully used as optimization tools in various applications, including the online tuning of the controller parameters [20-26]. "Particle Swarm Optimization (PSO) is an evolutionary computation optimization technique (a search method based on a natural system) developed by Kennedy and Eberhart" [27-30].

In this paper, number of fitness functions is defined to measure the performance of the proposed controllers. The proposed objective functions are designed to monomoze the over-current in the rotor circuit, to minimize losses as well as optimal power utilization. "Multi-objective optimization is used to find a Pareto front which is a set of acceptable solutions for conflected objective functions" [31-33]. MOPSO is used to determine the optimal gains for the PID controllers to both the stator-side converter and the rotor-side static converter of the DFIG. For the purpose of comparing the improvement obtained in the system dynamic performance with the application of the MOPSO procedures to design the controller gains, these results are compared with those obtained using the MultiObjective Genetic Algorithm (MOGA). A complete simulation model is developed for such machine under variable speed operation using MATLAB Simulink 
environment. Simulation results show that the proposed design approach is efficient to find the optimal parameters of the PID controllers and therefore improves the transient performance of the WECS over a wide range of operating conditions.

\section{MODELING OF THE STUDIED SYSTEM}

Figure 1 shows the proposed model for DFIG converting power from the wave to deliver power into the electric grid for a large range of wave variation. The stator of the DFIG is directly connected to the electric grid, whilst the rotor winding is fed through the back-toback PWM voltage-source inverters with a common DC link via slip rings to control the voltage applied to the rotor to allow DIFG to operate at a variety of speeds in response to wave changes. The rotor-side converter was implemented to provide an active and reactive power control by the field-oriented current control, as shown in Figure 2 . The reactive power can be controlled by controlling the $d$-axis rotor current. The stator active power $P_{s}$ can be independently controlled by controlling the $q$-axis rotor current. Figure 3 shows the overall control scheme of the grid-side converter. The grid-side converter is implemented to keep the dclink voltage constant regardless of the magnitude and direction of the rotor power. The control of the grid-side converter are organized in two loops; a DC-link current control loop, which controls the current through the grid filter, and DC-link voltage control loop that controls the dc-link voltage.

\section{DIGITAL SIMULATION RESULTS}

The proposed MOPSO strategy has been tested for validation using the DFIG whose ratings are given in the Appendix. The wave model of Figure 4 is adopted to generate a specific power reference and validate the good power tracking performances and therefore confirm the effectiveness of the proposed control

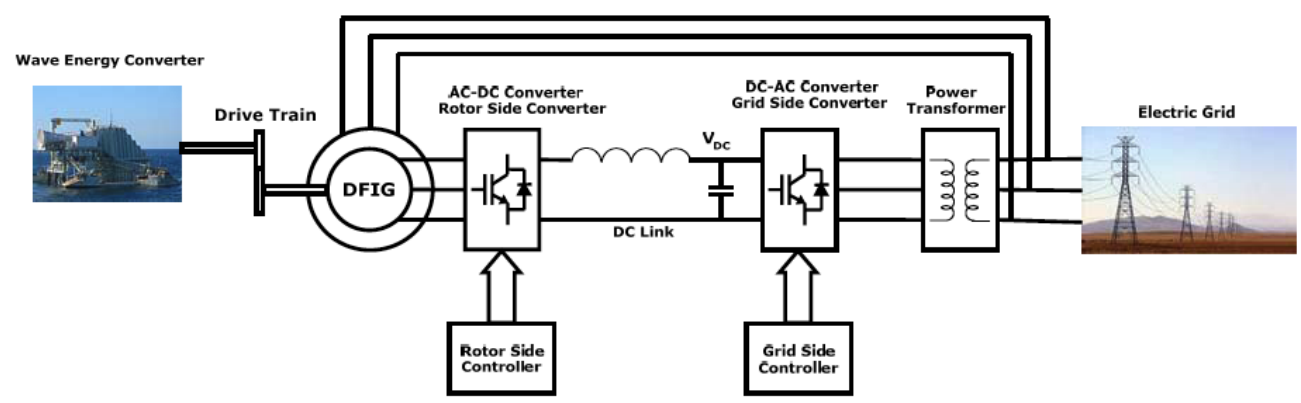

Figure 1: Schematic representation of Wave energy converter with Doubly-Fed Full-Controlled Induction Generator.

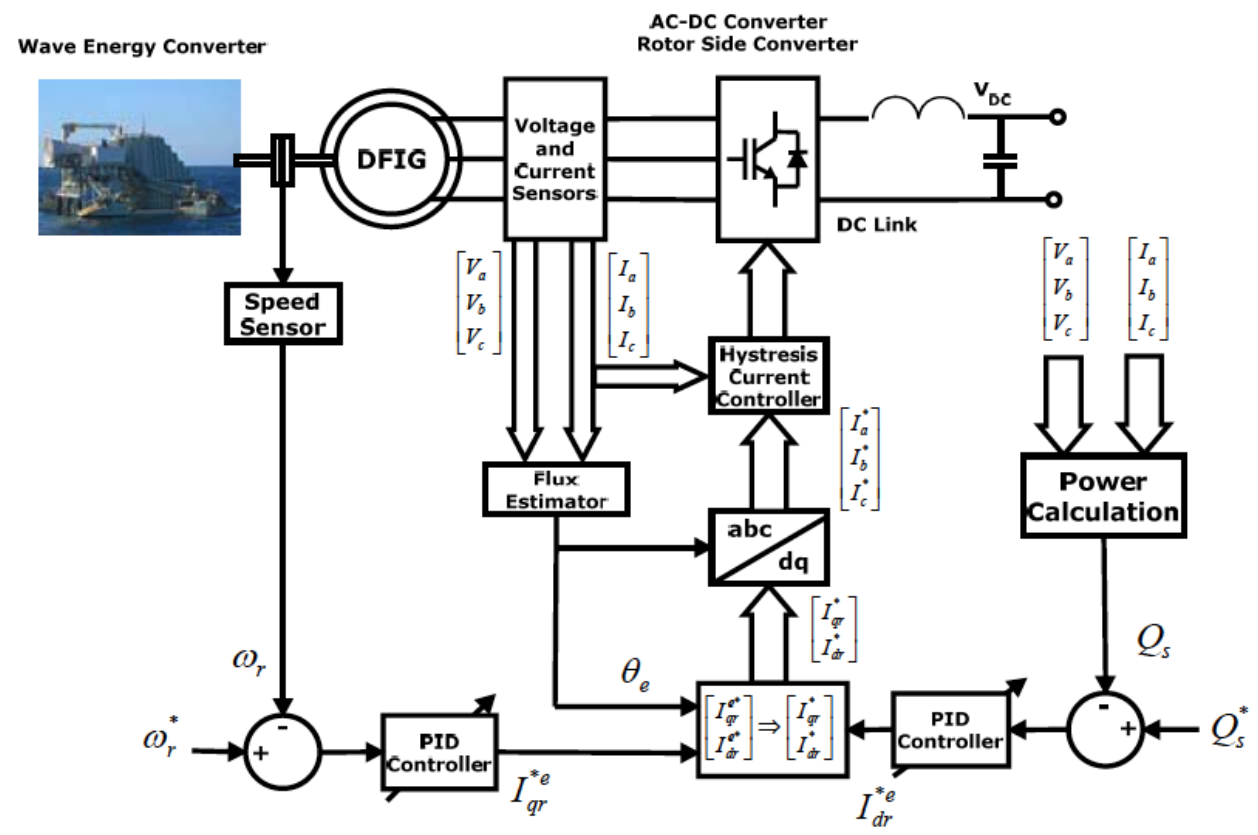

Figure 2: Rotor-side converter control. 


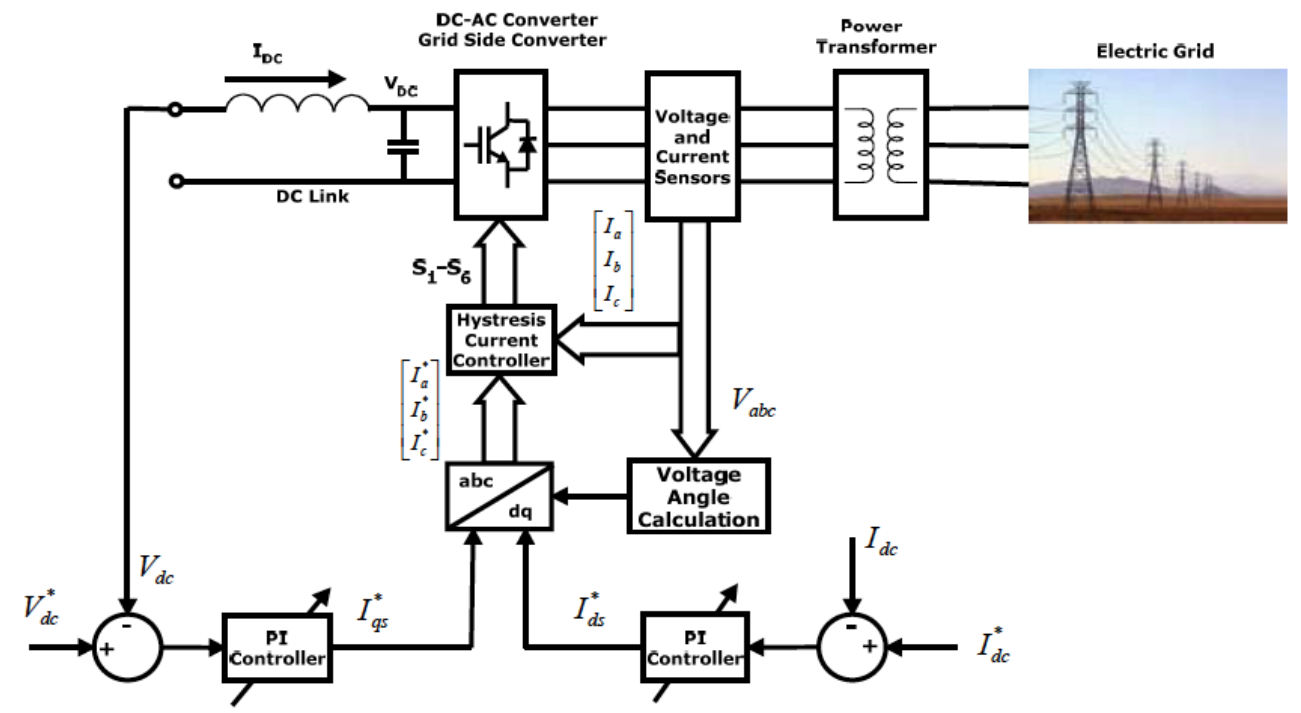

Figure 3: Stator-side converter control.

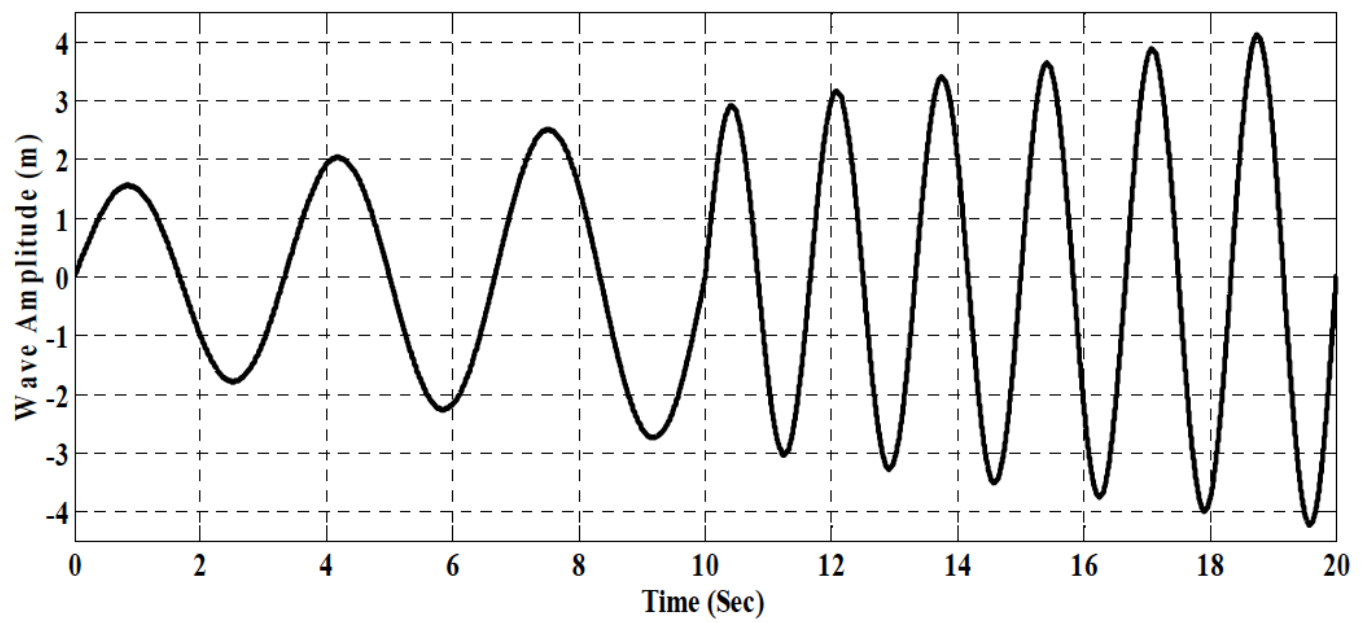

Figure 4: The wave model.

strategy based on MOPSO. To compare the improvement obtained in the system dynamic performance with the application of the MOPSO procedure to design the controller gains, these results are compared with those obtained using the MOGA. For the same operation condition, the MOGA and MOPSO were used to obtain the optimal gains for the controllers of the stator-side and the rotor-side converters.

In the GSC and the RSC control loops, there are four PID controllers and each of them has a proportional gain, an integral and differential gains. The behavior of the converter depends on the control system. If the controllers are tuned properly, it is possible to improve the GSC and RSC converter's performance during the transient disturbances. The MOGA and the MOPSO algorithms are applied to find automatically the optimal parameters of the GSC and the RSC controllers. The objective of the MOGA and the MOPSO is to find the optimal parameters of the four PID controllers, namely, four proportional gains $(K P 1, K P 2, K P 3$, and $K P 4)$, four integral gains $(K I 1$, $K I 2, K I 3$, and $K / 4)$ and four differential gains $(K D 1$, $K D 2, K D 3$, and $K D 4$ ) to optimize some fitness functions.

The following objective functions were used to measure the quality of the gains tuning to improve the system performance during the transient disturbances. These functions are represented by the weighted sum of the Normalised Mean Square Error (NMSE) deviations between output plant variables and desired values. The NMSE deviations between output plant variables and desired values are defined as: 


$$
\begin{aligned}
& J_{1}=N M S E_{V D C}=\frac{\sum\left(V_{D C}-V_{D C-r e f}\right)^{2}}{\sum\left(V_{D C-r e f}\right)^{2}} \\
& J_{2}=N M S E_{I D C}=\frac{\sum\left(I_{D C}-I_{D C-r e f}\right)^{2}}{\sum\left(I_{D C-r e f}\right)^{2}} \\
& J_{3}=N M S E_{\omega r}=\frac{\sum\left(\omega_{r}-\omega_{r-r e f}\right)^{2}}{\sum\left(\omega_{r-r e f}\right)^{2}} \\
& J_{4}=N M S E_{Q s}=\frac{\sum\left(Q_{s}-Q_{s-r e f}\right)^{2}}{\sum\left(Q_{s-r e f}\right)^{2}}
\end{aligned}
$$

The SOPSO finds a single optimal solution of the following objective function $\left(J_{0}\right)$ which combines several objective functions using specified or selected weighting factors:

$$
\mathrm{J}_{\mathrm{o}}=\int_{0}^{\mathrm{t}}\left(\alpha_{1} J_{1}+\alpha_{2} J_{2}+\alpha_{3} J_{3}+\alpha_{4} J_{4}\right) d t
$$

Where $\alpha_{1}=0.25, \alpha_{2}=0.25, \alpha_{3}=0.25, \alpha_{4}=0.25$ are selected weighting factors. $J_{1}, J_{2}, J_{3}, J_{4}$ are the selected objective functions. The weighting factors in the objective function $\left(J_{0}\right)$ are used to satisfy different design requirements. If a large value of $\alpha_{1}$ is used, then the objective is to minimize the error of the DC link voltage.

The main steps of the the optimal PID controller gains design procedure using MOPSO is an iterative scheme involving the following steps:

1. Initialize the population of the particle swarm with random values of gains which are restricted by the following minimum and maximum values:

$$
\begin{aligned}
& K_{P \min } \leq K_{P} \leq K_{P \max } \\
& K_{\text {Imin }} \leq K_{I} \leq K_{\text {Imax }} \\
& K_{D \text { min }} \leq K_{D} \leq K_{D \max }
\end{aligned}
$$

2. The feasibility of each particle is checked to make sure the particle satisfies the constraints.

3. All particles are initialized with random velocities.

4. The objective functions are used to evaluate the fitness of each particle in the swarm. The PID controller gains are assigned for each individual and the WECS-DFIG model is simulated to obtain the values of the objective functions.

5. Save the multi-objective fitness value of each particle in vector form. These vectors store the values of each gain of the PID controller. These values are copied in the $p_{\text {best }}$ vectors.

6. Check the Pareto optimality of the multi-objective fitness values of each particle. All non-dominated solutions are saved in the Pareto archive (external file)

7. The global gbest particle is randomly selected.

8. The velocity of each particle is updated using the following equation.

$\mathrm{V}_{\mathrm{id}}=\omega \times V_{i d}+C_{1} \times$ rand $_{1} \times$

$\left(P_{p d}-X_{i d}\right)+C_{2} \times$ rand $_{2} \times\left(P_{r d}-X_{i d}\right)$

Where $P_{i d}, P_{a d}$ are randomly chosen from the Pareto archive, $\omega$ is the inertia factor, $V_{i, d}$ is the velocity of the particle $\mathrm{i}$ in the d_th dimension, $\mathrm{c}_{1}$ and $\mathrm{c}_{2}$ are weights.

9. The position $\mathbf{X}_{\mathbf{i}, \mathrm{d}}$ of each particle is also updated using the following equation to maintain the particles within the feasible solution region.

$X_{i d}=X_{i d}+V_{i d}$

10. Evaluate the quality of each particle. If the fitness value of the particle is non-dominated, save it into the Pareto archive. In the Pareto archive, if a particle is dominated by a new one, then discard it.

11. Then, the new gbest is randomly selected. Two Pareto solutions are chosen randomly for $P_{r, d}, P_{i, d}$ from the Pareto archive.

12. Repeat the cycle, steps (8) to (11), until the predetermined maximum number of generations is reached or convergence is reached based on some desired single or multiple criteria.

In the calculation of the optimal gains by the GA and the PSO procedures, the objective is to improve the overall dynamic performance of the DFIG when it is subjected to severe electrical disturbances and faults in the electrical network. The dynamic simulations were carried out for a three phase short circuit next to the DFIG bus at time $t=0.2 \mathrm{~s}$, lasting for $0.2 \mathrm{~s}$. The gain values for the PSO and GA adjustment procedures are 
Table 1: Gains Adjustments for the PID Controllers of GSC and RSC Converters Using PSO and GA

\begin{tabular}{|c|c|c|c|c|}
\hline & SOGA & SOPSO & MOGA & MOPSO \\
\hline \hline $\mathrm{K}_{\mathrm{P} 1}$ & 14.1873 & 8.5814 & 11.0665 & 14.8185 \\
\hline $\mathrm{K}_{11}$ & 1.0937 & 2.2297 & 1.6190 & 2.6380 \\
\hline $\mathrm{K}_{\mathrm{D} 1}$ & 0.5205 & 0.9560 & 12.7491 & 1.4554 \\
\hline $\mathrm{K}_{\mathrm{P} 2}$ & 13.5941 & 11.9220 & 1.1730 & 1.3607 \\
\hline $\mathrm{K}_{12}$ & 1.1020 & 1.5187 & 1.6869 & 1.6929 \\
\hline $\mathrm{K}_{\mathrm{D} 2}$ & 0.2522 & 1.0467 & 15.8444 & 0.7970 \\
\hline $\mathrm{K}_{\mathrm{P} 3}$ & 12.3800 & 12.6762 & 0.9978 & 18.4986 \\
\hline $\mathrm{K}_{13}$ & 0.9673 & 1.0840 & 0.5987 & 1.4495 \\
\hline $\mathrm{K}_{\mathrm{D} 3}$ & 0.1949 & 0.9218 & 13.0007 & 1.0303 \\
\hline $\mathrm{K}_{\mathrm{P} 4}$ & 6.8077 & 11.9575 & 2.3141 & 10.2206 \\
\hline $\mathrm{K}_{14}$ & 1.7054 & 1.8599 & 1.1065 & 3.5095 \\
\hline $\mathrm{K}_{\mathrm{D} 4}$ & 0.4762 & 0.8695 & 1.1325 \\
\hline
\end{tabular}

presented in Table 1. The oscillations of the dc-link voltage, when applying the MOGA are slightly larger than when applying the MOPSO, as shown in Figure $\mathbf{5}$. However, the dc-link voltage oscillations in both designs do not affect the continuous operation of the WECS and consequently improving the DFIG dynamic performance. The grid-side converter current is shown in Figure 6-a, a reduction in the over-current can is easily be observed, when the gains are adjusted by the MOPSO as compared with those adjusted via MOGA, consequently contributes towards maintaining the converter in operation during the fault period. The gridside converter voltage dynamic behavior is shown in Figure 6-b. It is observed that with the use of gains obtained by MOGA the terminal voltage presents deeper sag as compared with those controllers with gains adjusted by the proposed MOPSO procedure. Figure 6-c presents the grid side converter active power behavior. It is observed that in the case when controllers with gains adjusted by MOPSO are used, the active power presents smaller oscillations as compared with the MOGA. Figure 6-d shows a reduction in the reactive power injected into the electrical network by the grid-side converter in case the controllers' gains are adjusted by the MOGA and MOPSO procedures. This implies that the transient performance of the WECS is improved using MOGA and MOPSO. Figure 7-a shows the rotor side converter voltage, where it can be observed that the over-voltage in the rotor circuit is reduced when the controllers' gains are those obtained with the MOGA and MOPSO procedures. Figure 7-b presents a reduction on the

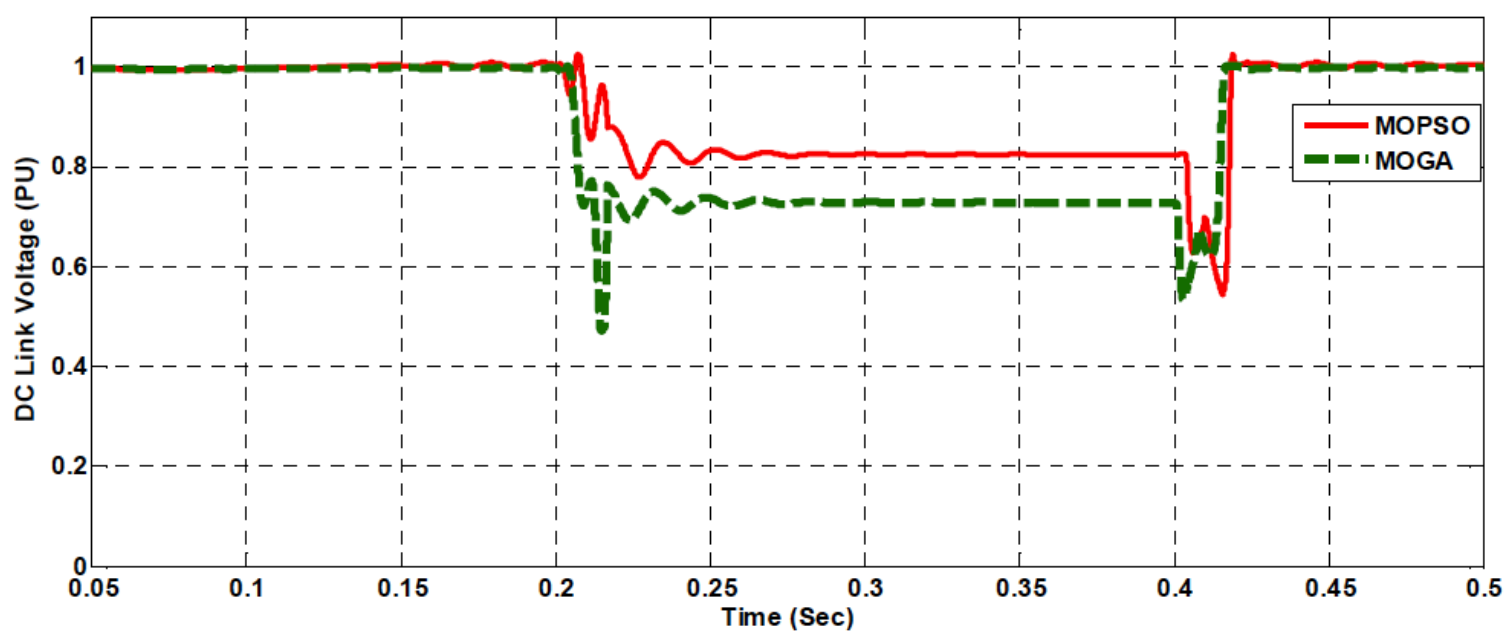

Figure 5: DC Link Voltage. 


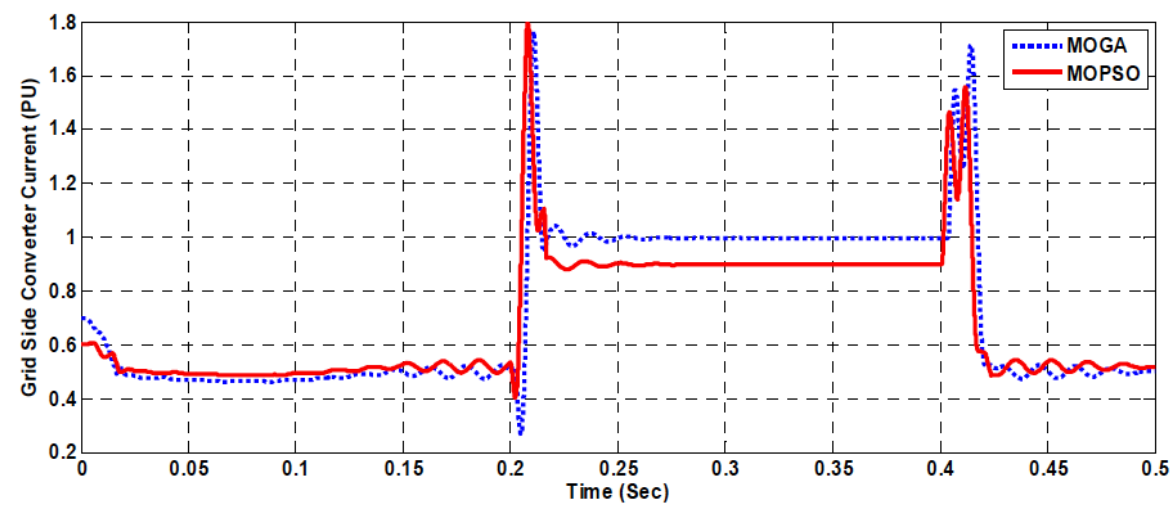

(a)

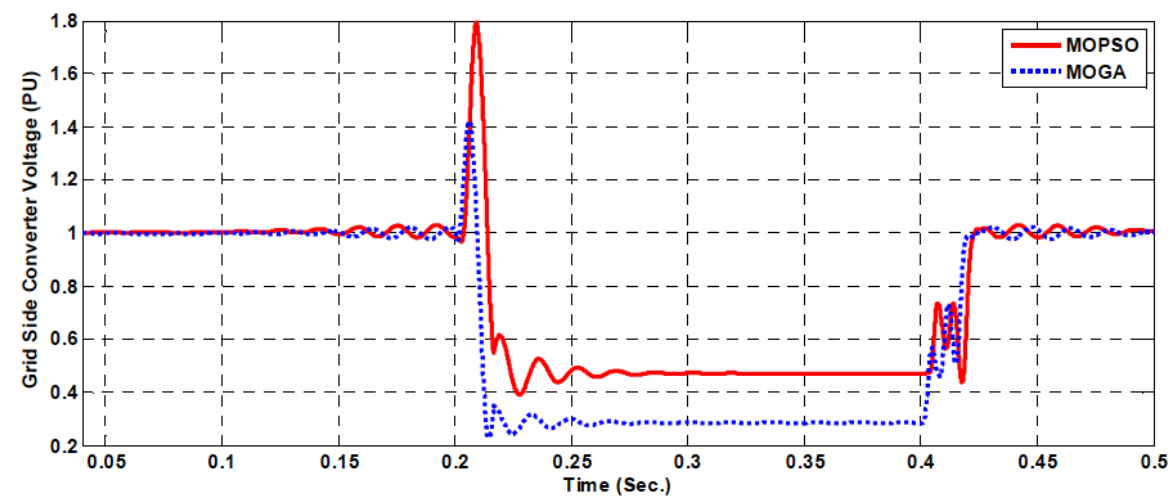

(b)

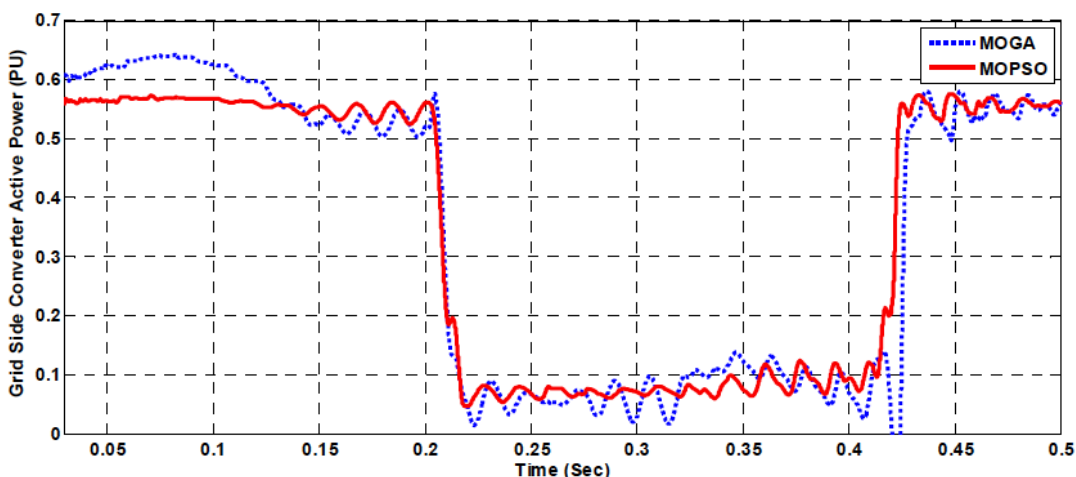

(c)

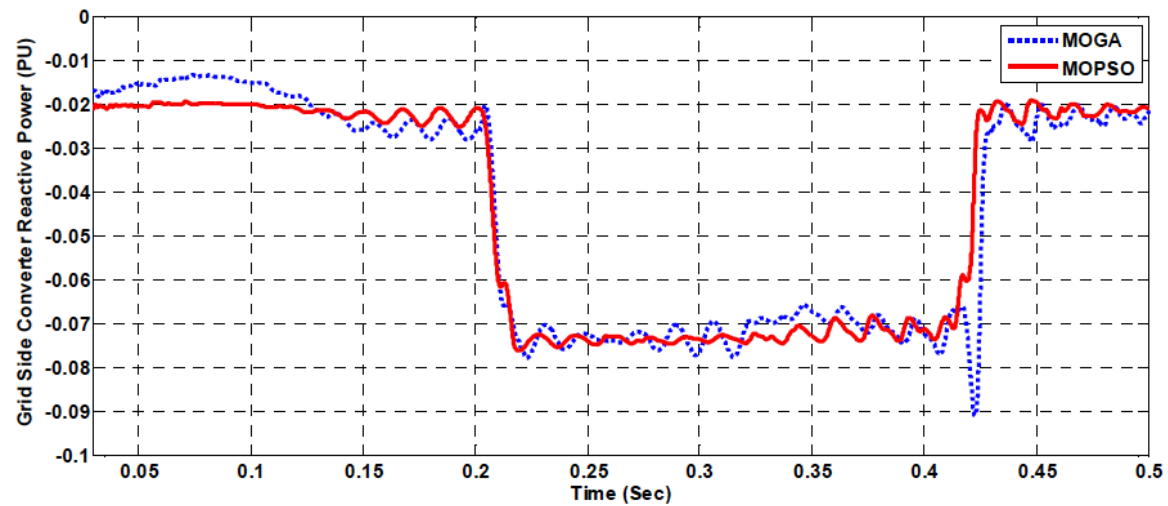

(d)

Figure 6: Grid Side Converter transient performance during the fault period.

(a) Grid Side Converter Current. (b) Grid Side Converter Voltage. (c) Grid Side Converter Active Power. (d) Grid Side Converter Reactive Power. 


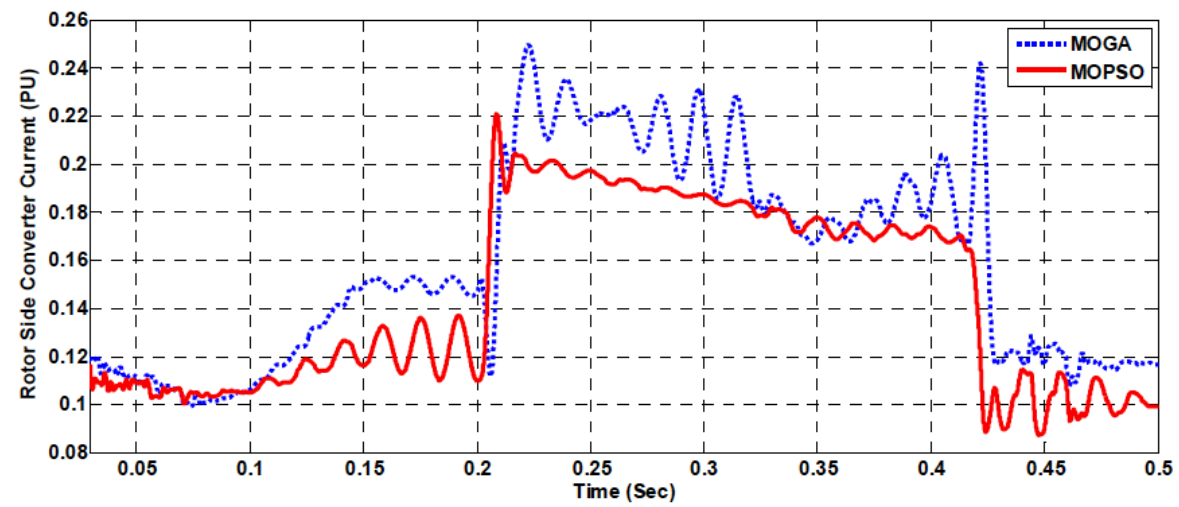

(a)

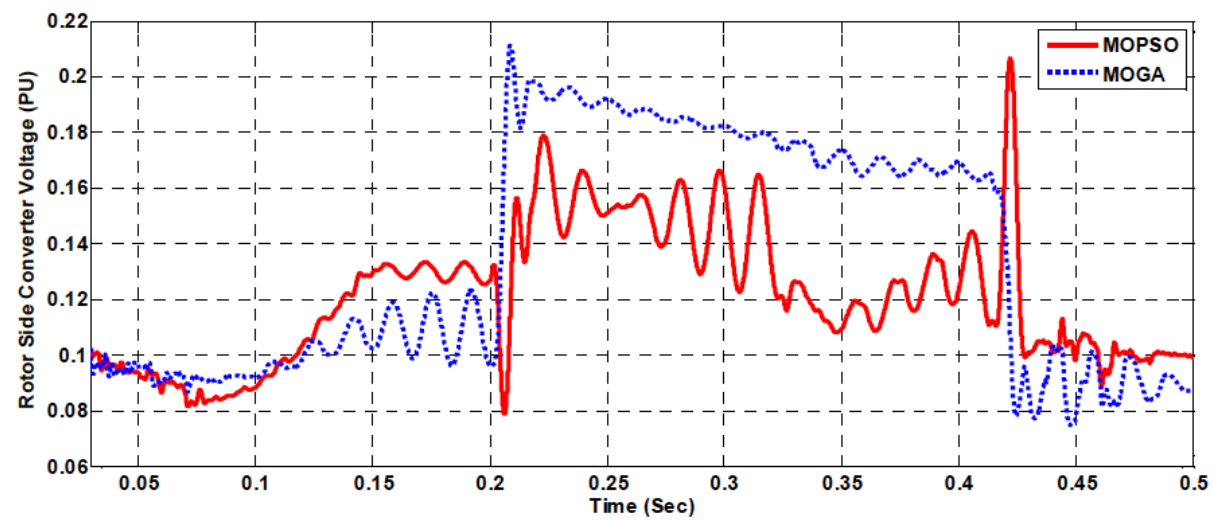

(b)

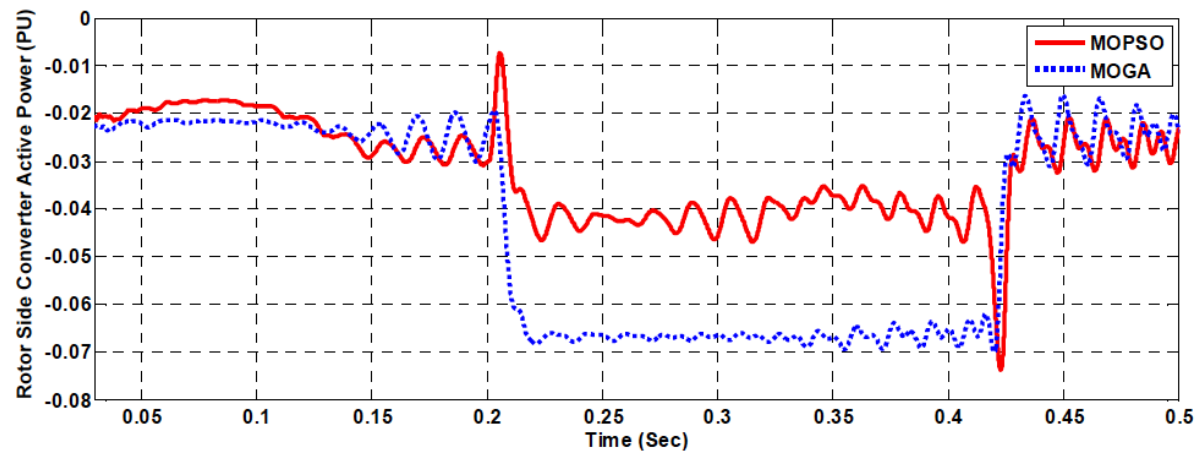

(c)

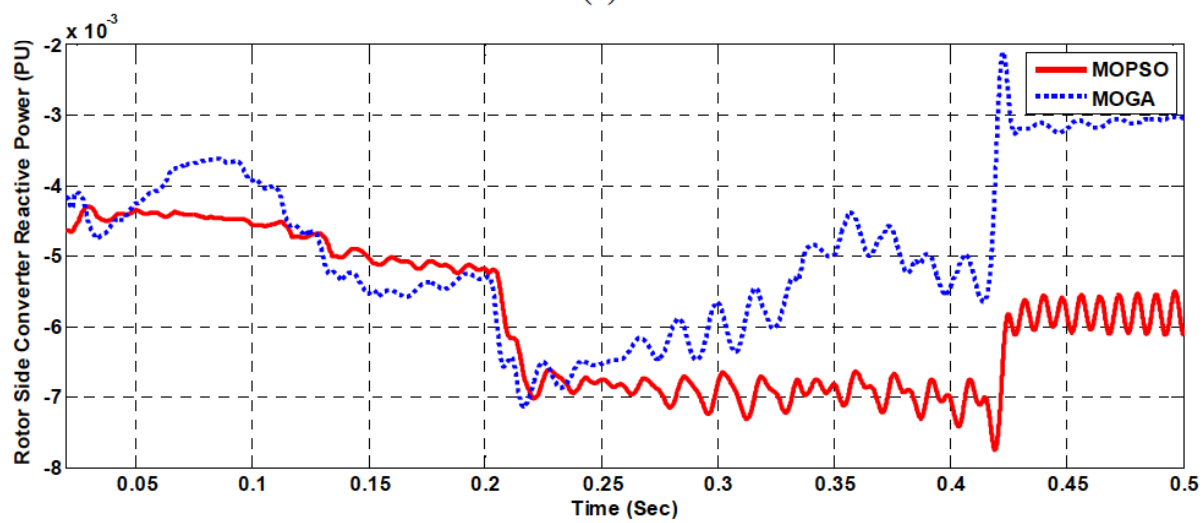

(d)

Figure 7: Rotor Side Converter transient performance during the fault period.

(a) Rotor Side Converter Current. (b) Rotor Side Converter Voltage. (c) Rotor Side Converter Active Power. (d) Rotor Side Converter Reactive Power. 
Table 2: System Dynamic Behavior Comparison

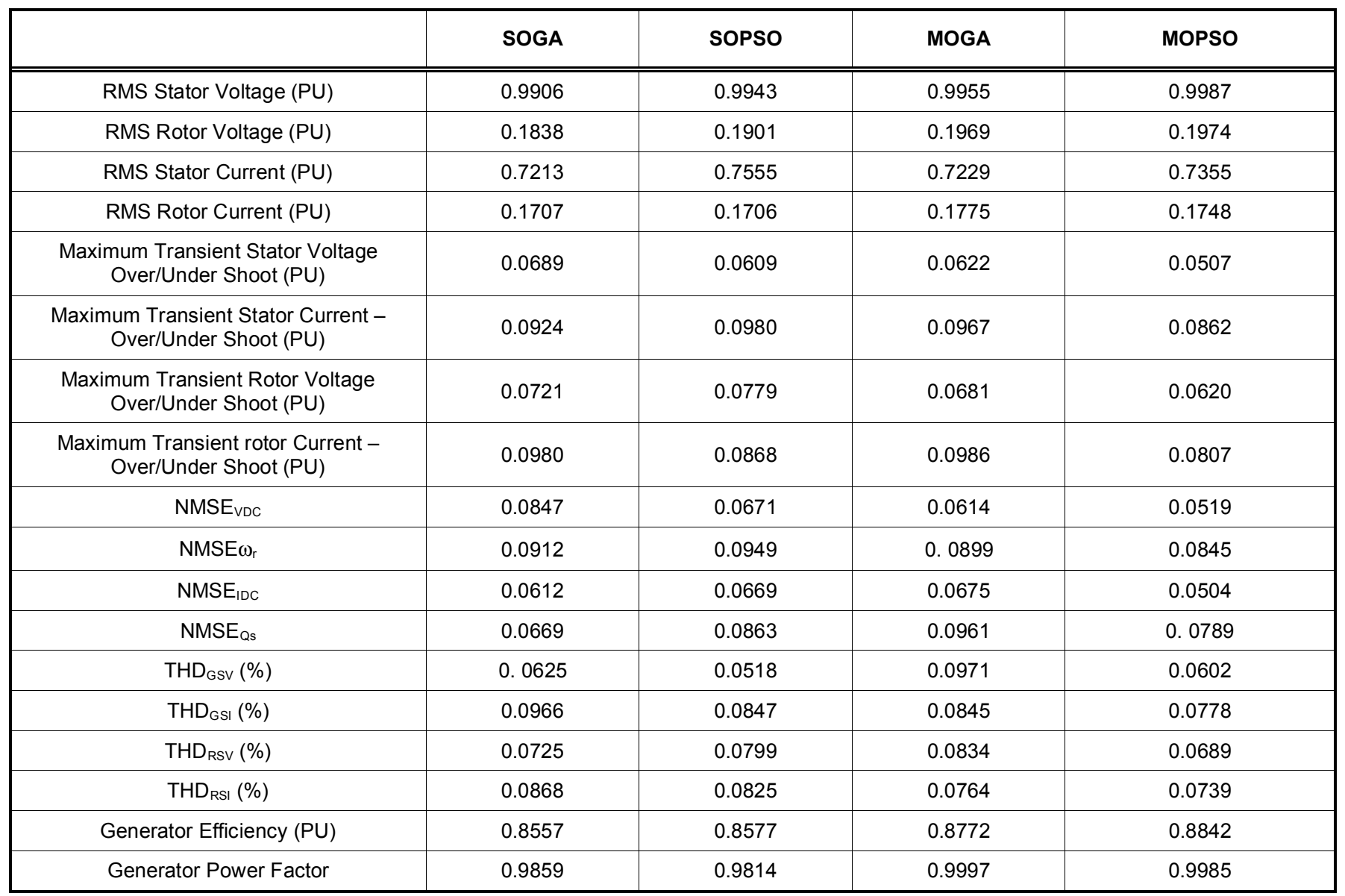

rotor side converter current oscillation when the gain adjustments are accomplished by the MOPSO as compared to the result with the MOPSO technique. Figures 7-c and 7-d illustrate the dynamic response of both rotor side converter active and reactive powers, for the cases of gains adjusted by MOPSO and by the MOGA procedures. It could be easily concluded that the proposed control strategies based on MOGA and MOPSO achieve satisfactory dynamic performances. Table 2 shows the system behavior comparison using the SOGA, SOPSO, MOGA and MOPSO based Self tuned controllers. The table illustrates the total harmonic distortion measurement in the three phase grid voltage waveforms, three phase grid current waveforms, three phase rotor voltage waveforms and three phase rotor current wave forms. The system produces less than $10 \%$ voltage and current THD which is compliant to IEC 6100-3-2.

\section{CONCLUSION}

This paper has presented the modeling and simulation of wave energy driven doubly-fed induction generator which is connected to the utility grid. The stator of the DFIG is directly connected to the AC mains, whilst the rotor winding is fed through the backto-back PWM voltage-source inverters with a common DC link via slip rings to control the voltage applied to the rotor to allow DIFG to operate at a variety of speeds in response to wave changes. The PID controllers are used to control both GSC and RSC converters and their parameters are optimally designed using the particle swarm optimization (PSO) algorithm and Genetic Algorithm (GA). Simulation studies are carried out and compared the results obtained with the proposed optimal PID controller parameters design using MOPSO with those using controllers adjusted by the MOPSO. Results show that the proposed design approach is efficient to find the optimal parameters of the PID controllers and improves the transient performance of the wave energy system over a wide range of operating conditions. THD levels of the converter output voltage has been estimated using fast Fourier transform which satisfies the IEEE 519-1992 standard. 


\section{APPENDIX}

\section{DFIG Parameters}

$$
\begin{aligned}
& \text { Nominal power, } P_{\text {base }}=660 \mathrm{KW} \\
& \text { Grid frequency, } f=60 \mathrm{~Hz} \\
& \text { Nominal voltage }(\mathrm{L}-\mathrm{L}), V_{\text {base }}=400 \mathrm{~V} \\
& \text { Stator resistance, } r s=0.03513 \mathrm{pu} \\
& \text { Stator inductance, } L / s=0.04586 \mathrm{pu} \\
& \text { Rotor resistance, } r r=0.03488 \mathrm{pu} \\
& \text { Rotor inductance, } L / r=0.04586 \mathrm{pu} \\
& \text { Mutual inductance, } L m=1.352 \mathrm{pu} \\
& \text { Pole pairs, } \mathrm{P}=2
\end{aligned}
$$

\section{WEC Parameters}

$H=0.726 m, T=5.612 \mathrm{~s}, d=1 \mathrm{~m}, \lambda=0.120 \mathrm{~m}, \mathrm{~V}_{p}=$ $500 \mathrm{~V}$.

\section{REFERENCES}

[1] Halamay D, Brekken T, Simmons A, McArthur S. Reserve requirement impacts of large-scale integration of wind, solar and ocean wave power generation. IEEE Trans Sustain Energy 2011; 2(3): 321-28. http://dx.doi.org/10.1109/TSTE.2011.2114902

[2] Fusco F, Ringwood J. Variability reduction through combination of wind and waves: A Irish case study. Energy 2010; 35: 314-25. http://dx.doi.org/10.1016/j.energy.2009.09.023

[3] Yang X, Song Y, Wang G, Wang M. A comprehensive review on the development of sustainable energy strategy and implementation in China. IEEE Trans Sustain Energy 2010; 1(2): 57-65.

http://dx.doi.org/10.1109/TSTE.2010.2051464

[4] Wang L, Chen Z-J. Stability Analysis of a Wave-Energy Conversion System Containing a Grid-Connected Induction Generator Driven by a Wells Turbine. IEEE Trans Energy Conver 2010; 25(2): 555-63.

[5] Amundarain M, Alberdi M, Garrido AJ, Garrido I. Modeling and Simulation of Wave Energy Generation Plants: Output Power Control. IEEE Trans Indust Electron 2011; 58(1): 10517.

[6] Benelghali S, Benbouzid MEH, Charpentier JF. Marine tidal current electric power generation technology: State of the art and current status. Proc 2007 IEEE IEMDC, Antalya (Turkey) 2007; 2: 1407-12.

[7] Fusco F, Ringwood JV. A Simple and Effective Real-Time Controller for Wave Energy Converters. IEEE Trans Sustain Energy 2013; 4(1): 21-30.

[8] Iwanski G, Koczara W. The DFIG-based power generation system with UPS function for variable-speed applications. IEEE Trans Ind Electron 2008; 55(8): 3047-54. http://dx.doi.org/10.1109/TIE.2008.918473
[9]

$\mathrm{Hu}$ J, He Y, Xu L, Williams BW. Improved control of DFIG systems during network unbalance using PI-R current regulators. IEEE Trans Ind Electron 2009; 56(2): 439-51. http://dx.doi.org/10.1109/TIE.2008.2006952

[10] Yamamoto $M$, Motoyoshi $O$. Active and reactive power control for doubly-fed wound rotor induction generator. IEEE Trans Power Electron 1991; 6(4): 624-29.

http://dx.doi.org/10.1109/63.97761

[11] Pena R, Clare JC, Asher GM. Doubly fed induction generator using back-to-back PWM converters and its application to variable speed wind-energy generation. IEE Proc Electr Power Appl 1996; 143(3): 231-41.

[12] Muller S, Deicke M, De Doncker RW. Doubly fed induction generator system for wind turbines. IEEE Ind Appl Mag 2002; 8(3): 26-33. http://dx.doi.org/10.1109/2943.999610

[13] Pena R, Clare JC, Asher GM. Doubly fed induction generator using back-to-back PWM converters and its application to variable-speed wind-energy generation. IEE Proc Electr Power Appl 1996; 143(3): 231-41. http://dx.doi.org/10.1049/ip-epa:19960288

[14] Tapia A, Tapia G, Ostolaza JX, Saenz JR. Modeling and control of a wind turbine driven doubly fed induction generator. IEEE Trans Energy Conver 2003; 18(2): 194-204. http://dx.doi.org/10.1109/TEC.2003.811727

[15] Tang T, Xu L. A flexible active reactive power control strategy for a variable speed constant frequency generating system. IEEE Trans Power Electron 1995; 10(4): 472-77. http://dx.doi.org/10.1109/63.391945

[16] Almeida RG, Peças Lopes JA, Barreiros JAL. Improving Power System Dynamic Behavior Through Doubly Fed Induction Machines Controlled by Static Converter Using Fuzzy Control. IEEE Trans Power Syst 2004; 19: 1942-50. http://dx.doi.org/10.1109/TPWRS.2004.836271

[17] Storn R, Price K. Minimizing the real functions of the ICEC'96 contest by differential evolution. Proc IEEE Int Conf Evolutionary Computing 1996; 842-44. http://dx.doi.org/10.1109/ICEC.1996.542711

[18] Storn R, Price K. Differential evolution- a simple and efficient adaptive scheme for global optimization over continuous spaces. ICSI Technical Report TR-95 -012, Berkeley, CA 1995.

[19] Yang L, Yang GY, Xu Z, Dong ZY, Wong KP, Ma X. Optimal controller design of a doubly-fed induction generator wind turbine system for small signal stability enhancement. Generation, Transmission \& Distribution, IET 2010; 4(5): 57997.

[20] Abido MA. A novel approach to conventional power system stabilizer design using tabu search. Int J Electr Power Energy Syst 1999; 21(6): 443-54.

http://dx.doi.org/10.1016/S0142-0615(99)00004-6

[21] Abido MA. Robust design of multimachine power system stabilizers using simulated annealing. IEEE Trans Energy Conver 2000; 15(3): 297-304. http://dx.doi.org/10.1109/60.875496

[22] Qiao W, Venayagamoorthy GK, Harley RG. Design of optimal PI controllers for doubly fed induction generators driven by wind turbines using particle swarm optimization. Proc Int Joint Conf Neural Network, (Canada) 2006; 1982-87.

[23] Vieira JPA, Nunes MVA, Bezerra UH, Do Nascimento AC. Designing optimal controllers for doubly fed induction generators using genetic algorithm. IET Gener Transm Distrib 2009; 3(5): 472-84. http://dx.doi.org/10.1049/iet-gtd.2008.0239

[24] Vieira J, Nunes M, Bezerra UH. Design of optimal PI controllers for doubly fed induction generators in wind turbines using genetic algorithm" Power and Energy Society General Meeting - Conversion and Delivery of Electrical Energy in the $21^{\text {st }}$ Century 2008; $1-7$. 
[25] Serra G, Bottura C. Genetic Approach for Neural Scheduling of Multiobjective Fuzzy PI Controllers. Int Symp Evolving Fuzzy Syst 2006.

[26] Ruiz-Cruz R, Sanchez EN, Ornelas-Tellez F, Loukianov AG, Harley RG. Particle Swarm Optimization for Discrete-Time Inverse Optimal Control of a Doubly Fed Induction Generator. IEEE Trans Cybernet 2012; 99: 1-12.

[27] Kennedy J, Eberhart R. Particle swarm optimization. Proc IEEE Int Conf Neural Netw 1995; 4: 1942-48.

[28] Shi Y, Eberhart R. Empirical study of particle swarm optimization. Proceedings of the 1999 Congress on Evolutionary Computation 1999; 3.

[29] Eberhart R, Shi Y. Particle swarm optimization: developments, applications and resources. Proceedings of the 2001 Congress on Evolutionary Computation, 2001; 1: 81-86.
[30]

Shi Y, Eberhart R. Parameter Selection in Particle Swarm Optimization. Proc Seventh Annual Conf Evolutionary Progr 1998; 591-601. http://dx.doi.org/10.1007/BFb0040810

[31] Ngatchou P, Zarei A, El-Sharkawi A. Pareto Multi Objective Optimization. Intelligent Systems Application to Power Systems, 2005. Proceedings of the 13th International Conference on 6-10 Nov 2005; 84-91.

[32] Berizzi A, Innorta M, Marannino P. Multiobjective optimization techniques applied to modern power systems In 2001 IEEE Power Engineering Society Winter Meeting, 2001.

[33] Coello Coello CA, Lechuga MS. MOPSO: A proposal for multiple objective particle swarm optimization. IEEE Proceedings World Congress on Computational Intelligence 2003; $1051-56$

Received on 28-12-2013

Accepted on 05-03-2014

Published on 25-03-2014

DOI: http://dx.doi.org/10.6000/1929-6002.2014.03.01.4

(C) 2014 Adel A.A. Elgammal; Licensee Lifescience Global.

This is an open access article licensed under the terms of the Creative Commons Attribution Non-Commercial License (http://creativecommons.org/licenses/by-nc/3.0/) which permits unrestricted, non-commercial use, distribution and reproduction in any medium, provided the work is properly cited. 